\title{
Industrial and Economic Importance of a Bacterium Lactobacillus Plantarum: A Review
}

\author{
Asfaw Tora Kacho* \\ Applied Microbiology, Department of Biology, College of Natural and Computational Science Wolaita Sodo \\ University, P.O. box 138, Ethiopia
}

*Corresponding Author: Asfaw Tora Kacho, Applied Microbiology, Department of Biology, College of Natural and Computational Science Wolaita Sodo University, P.O. box 138, Ethiopia

\begin{abstract}
Among LAB, Lactobacillus plantarum is an important culture for preservation of food and fermented food products such as vegetables, sausage products and silages, brine olives, sauerkraut, cassava, and kimchi. Lactobacillus plantarum completes the final stage of natural fruit and vegetable fermentations due to its higher acid tolerance than other LAB. Moreover, Lactobacillus plantarum has been used as a starter culture in sourdough bread, meat products, and wine. Its strains may also have probiotic characteristics and potentially several biotherapeutics applications. The present work is a review of various uses of Lactobacillus plantarum for which the researchers explored several resources including the PubMed database, Journals and online archives up to October 2018. The review in its analysis signifies the vital utility of Lactobacillus plantarum in various prospective. Lactobacillus plantarum is safe to be used in food products. This probiotic has been studied by several authors that used different agro-residue substrates for biomass production, and it has been studied for its metabolites of interest, especially lactic acid. Recently, the application of Lactobacillus plantarum in health food application has shown potential. There is now interest in the isolation and identification of potential strains from local resources for food and health applications. And, with recent advances in biotechnology, the economic contributions that these organisms can make in biotechnological applications and industrial processes can be exploited further for large scale benefit of mankind.
\end{abstract}

Keywords: Bioprospecting, Lactobacillus plantarum, microaerobiosis, Metabolic engineering, triple-phase process

\section{INTRODUCTION}

Lactic acid bacteria (LAB) are industrially important food grade bacteria and known for their fermentative, nutritional, and health benefits (Badr et al., 2005). The application of LAB and their metabolites for the preservation of food against spoilage has generated the interest towards their isolation and identification (Cleveland et al., 2001). Among LAB, Lactobacillus plantarum is an important culture for preservation of food and fermented food products such as vegetables, sausage products and silages, brine olives, sauerkraut, cassava, and kimchi. Lactobacillus plantarum completes the final stage of natural fruit and vegetable fermentations due to its higher acid tolerance than other LAB (Fleming, 1982). Moreover, Lactobacillus plantarum has been used as a starter culture in sourdough bread, meat products, and wine. Its strains may also have probiotic characteristics and potentially several biotherapeutics applications. From the nutritional point of view, there is a growing interest of professionals and consumers in healthier diets that, in addition to providing basic nutrients, will also have beneficial effects on health, and probiotics are among the most important components of such diets (Céspedes et al., 2013). The current definition of probiotics, given by the World Health Organization, states that probiotics are live microorganisms that, when administered in adequate amounts in diets, will confer health benefits for the host, human or animal. Bacteria of the genera Lactobacillus and Bifidobacterium are classified among the main probiotics considered safe for food and feed use, and they are produced in industrial scales (Siezen et al., 2011). Therefore, there is a great interest in screening for new potentially probiotic strains of LABs, such as Lactobacillus plantarum.

Traditionally, probiotics are generally added to or are components of dairy foods. However, there has been a growing demand for probiotics by non-dairy consumers due to increasing vegetarianism as a 
dietary preference throughout the world, and a large part of the world population has allergies to dairy products caused either by lactose or milk proteins (Jacobsen et al., 1999). These issues, associated with concerns of the occurrence of bovine spongiform encephalopathy by some consumers, especially in Europe, have increased the demand for all animal-free foods (Kandler et al., 1986) and there is a strong growing demand for new products in these markets. In the case of probiotics, it would be highly desirable if technology could deliver biosystems for cell growth free of any animal components to prevent the transfer of these constituents to the final product (Jaiswal et al., 2012).

Among probiotic bacteria or potentially probiotics depending on the strain, Lactobacillus plantarum is a versatile lactic acid bacterium found in a variety of foods and other environments such as the human gastrointestinal-tract. Lactobacillus plantarum is safe to be used in food products (Dallagnol et al., 2013). This probiotic has been studied by several authors that used different agro-residue substrates for biomass production, and it has been studied for its metabolites of interest, especially lactic acid. Recently, the application of Lactobacillus plantarum in health food application has shown potential. There is now interest in the isolation and identification of potential strains from local resources for food and health applications.

\section{TAXONOMY OF LACTOBACILLUS PLANTARUM}

\subsection{Scientific Classification}

Lactobacillus plantarum is a nonpathogenic Gram-positive, able-to-form-chains, catalase negative, nonspore forming, homo-fermentative rod. It ferments hexoses exclusively to lactic acid but can also ferment pentoses and/or gluconate and then produce lactic and acetic acid thus called facultatively heterofermentative Lactobacillus. Furthermore, it can ferment malic acid to lactic acid and carbon dioxide and citric acid to diacetyl, acetoin, and carbon dioxide (Kandler and Weiss, 1986).

\subsection{The Species Lactobacillus Plantarum}

Lactobacillus plantarum is one of bacterial species in the huge and relatively diverse genus of Lactobacillus, which comprises about 90 validly named species and subspecies. By tradition, the Lactobacillus spp. have been divided into three functional groups depending on their fermentation abilities; the obligate homofermentatives (Group I), the facultative heterofermentatives (Group II) and the obligate heterofermentatives (Group III) (Kandler and Weiss 1986). Group I ferment hexoses exclusively to lactic acid, and can't ferment gluconate or pentoses, while Group II also ferments hexoses to lactic acid but is additionally able to ferment pentoses and/or gluconate. Group III ferments hexoses to lactic acid, acetic acid and/or ethanol and carbon dioxide. Lactobacillus plantarum is facultatively heterofermentative. The type strain of Lactobacillus plantarum is ATCC 14917T (Kandler and Weiss 1986).

Lactobacillus plantarum differs from many other Lactobacillus spp. in the following points:

Lactobacillus plantarum has a relatively large genome in comparison with many other Lactobacillus spp. This indicates an adaptive ability for many different conditions (Kleerebezem et al. 2003). Lactobacillus plantarum can ferment many different carbohydrates. Lactobacillus plantarum has a high growth requirement for manganese and can accumulate high intercellular levels of manganese (Archibald and Fridovich 1981b). Manganese provides a defence for Lactobacillus plantarum against oxygen toxicity by the reduction of oxygen free radicals to hydrogen peroxide $\left(\mathrm{H}_{2} \mathrm{O}_{2}\right.$; Archibald and Fridovich 1981a). The produced $\mathrm{H}_{2} \mathrm{O}_{2}$ can then be converted to oxygen $\left(\mathrm{O}_{2}\right)$ and water by manganese cofactored pseudocatalase (Kono and Fridovich 1983a, 1983b). Lactobacillus plantarum have a high tolerance to low pH (Daeschel and Nes 1995). The fact that Lactobacillus plantarum frequently predominate in spontaneously, lactic acid fermented foods where the final $\mathrm{pH}$ usually is below 4.0, and also can survive the passage through the acid conditions of the human stomach (Johansson et al,. 1993), points to the high resistance to acid conditions. Lactobacillus plantarum can possess tannase activity (Osawa et al,. 2000; Vaquero et al . 2004) and are also able to metabolise phenolic acids (Barthelmebs et al., 2000; Barthelmebs et al, 2001). Furthermore, a strain of Lactobacillus plantarum (IFPL935) was able to metabolize a flavan-3-ol enriched grape seed extract by means of galloylesterase, decarboxylase and benzyl alcohol dehydrogenase activities (Tabasco et al. 2011). 


\subsection{Abundance of Lactobacillus Plantarum}

Among probiotic bacteria or potentially probiotics depending on the strain, Lactobacillus plantarum is a versatile lactic acid bacterium found in a variety of foods and other environments such as the human gastrointestinal-tract (Dallagnol et al., 2013). Lactobacillus plantarum is safe to be used in food products. This probiotic has been studied by several authors that used different agro-residue substrates for biomass production, and it has been studied for its metabolites of interest, especially lactic acid. Such substrates include malt, wheat, barley extracts, molasses stillage, sugar beet molasses, coffee husks, tamarind seed powder, ground nut oil cake, wheat brans, rice brans, bengal gram powder, black gram flour, green gram flour, barley, millet, ragi, oats, corn flour, rice flour, york cabbage, quinoa, and wheat slurry (Dallagnol et al., 2013).

Lactobacillus plantarum is commonly found in many fermented food products including sauerkraut, pickles, brined olives, Korean kimchi, Nigerian Ogi, sourdough, and other fermented plant material, and also some cheeses, fermented sausages, and stockfish. The high levels of this organism in food also makes it an ideal candidate for the development of probiotics.

Lactobacillus plantarum has a high tolerance to low $\mathrm{pH}$, showing its high resistance to acidic conditions (Daeschel and Nes,1995). Therefore, it frequently predominates in spontaneously lactic acid fermented foods where the $\mathrm{pH}$ usually is below 4.0. It also survives in the acid conditions of the human stomach (Johansson et al., 1993). L. plantarum frequently occurs spontaneously, mostly in those lactic acid fermented foods where the food is based on plant material such as brined olives (Fernández Gonzalez et al., 1993), capers (caper berries; Pulido et al., 2005), sauerkraut (Dedicatoria et al., 1981), salted gherkins (McDonald et al., 1993), sourdough (Lonner and Ahrne, 1995), Nigerian ogi (made from maize or sorghum; Johansson, 1995a), Ethiopian sourdough made out of tef (Eragrostistef; Nigatu, 1998), and cassava (Oyewole and Odunfa, 1990; Moorthy and Mathew, 1998). This indicates that individuals consuming lactic acid fermented products of plant origin also consume large amounts of Lactobacillus plantarum.

\section{Products of LaCtobacillus Plantarum}

\subsection{Silage}

Lactobacillus plantarum is the most common bacterium used in silage inoculants. During the anaerobic conditions of ensilage, these organisms quickly dominate the microbial population, and, within 48 hours, they begin to produce lactic and acetic acids via the Embden-Meyerhof Pathway, further diminishing their competition. Under these conditions, L. plantarum strains producing high levels of heterologous proteins have been found to remain highly competitive. This quality could allow this species to be utilized as an effective biological pretreatment for lignocellulosic biomass (Kim et al, 1995).

\subsection{Therapeutics}

Lactobacillus plantarum has significant antioxidant activities and also helps to maintain the intestinal permeability (Bested et al., 2013). It is able to suppress the growth of gas producing bacterium in the intestines and may have benefit in some patients who suffer from IBS (Bixquert Jiménez, 2009). Lactobacillus plantarum has been found in experiments to increase hippocampal brain derived neurotrophic factor which means L. plantarum may have a beneficial role in the treatment of depression. The ability of $L$. plantarum to survive in the human gastro-intestinal tract makes it a possible in vivo delivery vehicle for therapeutic compounds or proteins.

\subsection{Activity Against Aids-Defining Illnesses}

As a result of initial HIV infection, the gut has been found to be a prime center of immune activity (Silvestri et al., 2014). The immune systems' Paneth cells of the gut attack HIV by producing IL-1 $\beta$, which results in massive collateral damage - sloughing of tight intestinal lining (witnessed as severe diarrhea). This destruction of the gut lining allows other pathogens, e.g. Cryptococcus species to invade, resulting in an AIDS defining illness such as Cryptococcosis (this pathogen represents 60\%$70 \%$ of all AIDS defining cases, but not necessarily only the gut). Lactobacillus plantarum is able to reduce (destroy) IL-1 $\beta$, resolving inflammation, and accelerating gut repair within hours (Silvestri et al., 2014). 


\subsection{Antagonistic Effects Against Adverse Microorganisms}

The current definition of probiotics has changed somewhat since Fuller (1989). Today probiotics are "live microorganisms with beneficial health effects when administrated to animals and humans", but even so, the original concept of counteracting deleterious bacteria in the GI-tract still remains. A crucial question is what components of the intestinal flora that should be suppressed?

That it would be beneficial if probiotics can inhibit pathogens is self-evident, but true pathogens are not supposed to be part of the resident microbiota. Examples of frequently occurring components of the human intestinal microbiota that can have negative health implications and therefore should be counteracted are Bacteroides fragilis and the different genera and species of the family Enterobacteriaceae (for example, Escherichia coli and Klebsiella pneumoniae). Members of the Enterobacteriaceae family can be found in high numbers in the normal microbiota are also frequently involved in abdominal infections and sepsis. They synthesise lipopolysaccharides (LPS; also called endotoxins) associated to the cell walls. LPS have strong proinflammatory effects if it enters the circulation.

The ability of Lactobacillus plantarum to produce antimicrobial substances helps them survive in the gastro-intestinal tract of humans. The antimicrobial substances produced have shown significant effect on Gram-positive and Gram-negative bacteria.

Lactobacillus plantarum 299v possesses anti-microbial activity in vitro against potentially pathogenic species such as Listeria monocytogenes , Bacillus cereus, Escherichia coli , Yersinia enterocolitica, Citrobacter freundii , Enterobacter cloacae and Enterococcus faecalis (Jacobsen et al. 1999), and relatively strong antagonistic properties against Salmonella enterica subsp. enterica (Hütt et al. 2006), and more intermediate antagonistic activity against Helicobacter pylori (Hütt et al . 2006). Lactobacillus plantarum 299v has also strong inhibitory effect in vitro against Streptococcus mutans and Candida albicans which both are suggested to be associated to caries (Hasslöf et al. 2010). The ability of Lactbacillus plantarum $299 \mathrm{v}$ to mitigate S. mutans (biofilm formation in vitro) was confirmed by Söderling et al. (2011).

When healthy volunteers consumed a mixture of lactobacilli strains, including Lactobacillus plantarum $299 \mathrm{v}$, there was a decrease in the level of Gram-negative anaerobes, Enterobacteriaceae and sulphite-reducing clostridia (Johansson et al., 1993).

Enterobacteriaceae is a family including many pathogenic and opportunistically pathogenic taxa, and even normally non-pathogenic taxa of Enterobacteriaceae can have a pathogenic potential in situations where the immunological defence of the host is failing. The inhibitory effect of Lactobacillus plantarum 299v against Enterobacteriaceae (Mao et al. 1996a; Adawi et al. 1997; Wang et al. 2001; Osman et al. 2005) and Gram-negative anaerobes (Mao et al . 1996a) has been demonstrated in vivo, in rat-models simulating severe clinical conditions.

Lactobacillus plantarum 299v inhibits adhesion of enteropathogenic and enterohemorrhagic Escherichia coli to intestinal epithelial cell-cultures by inducing mucin expression in the epithelial cells, i.e. intestinal epithelial cells produced more mucin which limited the access for E. coli to bind to their surface (Mack et al .1999; Mack et al . 2003). The ability of Lactobacillus plantarum 299v to reduce secretory response of intestinal epithelial cells to enteropathogenic E. coli (EPEC) has been shown in vitro (Michail and Abernathy, 2002). The observed effect was due to reduced attachment of EPEC to epithelial cells (Michail and Abernathy, 2002). Furthermore, Lactobacillus plantarum 299v increased Muc3 protein and mRNA expression in vivo (rats) in jejunum and ileum (Dykstra et al. 2011).

\section{CONCLUSION AND RECOMMENDATION}

According to the studies cited in different literatures Lactobacillus plantarum reported as the most effective and playing important roles as dominant bacteria in biotechnological applications as well as industrial processes and products. And, with recent advances in biotechnology, the economic contributions that these organisms can make in biotechnological applications and industrial processes can be exploited further for large scale benefit of mankind. Therefore, we encourage any bio prospecting company to access this genetic resource for its potentials in biotechnological applications as well as industrial processes and products for access and benefit sharing. 


\section{ACKNOWLEDGEMENT}

The author would like to express deepest gratitude to deepest gratitude to Eyasu Wada for his contribution in sharing his knowledge by reading and editing the manuscript.

\section{REFERENCES}

[1] Adawi, D., Kasravi, F.B., Molin, G., and Jeppsson, B. (1997). Effect of Lactobacillus supplementation with and without arginine on liver damage and bacterial translocation in an acute liver injury model, Hepatology 25: 642-647.

[2] A.K. Jaiswal, S. Gupta, N. Abu-Ghannam, (2012). Optimisation of lactic acid fermentation of York cabbage for the development of potential probiotic products Int J Food Sci Technol, 47, pp. 1605-1612

[3] A.M. Dallagnol, M. Pescuma, G. Font De Valdez, G. Rollá, (2013). Fermentation of quinoa and wheat slurries by Lactobacillus plantarum CRL 778: proteolytic activity Appl Microbiol Biotechnol, 97 pp. 3129-3140

[4] Archibald, F. and Fridovich, I. (1981a). Manganese and defence against oxygen toxicity in Lactobacillus plantarum, J. B acteriol. 145: 442-451.

[5] Archibald, F. and Fridovich, I. (1981b). Manganese, superoxide dismutase, and oxygen tolerance in some lactic acid bacteria, J. Bacteriol. 146: 928-936.

[6] Bested, Alison C; Logan, Alan C; Selhub, Eva M (2013). "Intestinal microbiota, probiotics and mental health: from Metchnikoff to modern advances: Part II - contemporary contextual research". Gut Pathogens. 5 (1): 3.

[7] Badr, S., Karem, A., Hussen, H., El-Hadedy, D. (2005). Characterization of nisin produced by Lactococcus lactis. Int. J. Agri. Biol. 7:499-503.

[8] Barthelmebs, L., Divies, C., and Cavin, J-F. (2000). Knockout of the pcoumarate decarboxylase gene from Lactobacillus plantarum reveals the existence of two other inducible enzymatic activities involved in phenolic acid metabolism, Appl. Environ. Microbiol. 66: 3368-3375.

[9] Bixquert Jiménez, M. (2009). "Treatment of irritable bowel syndrome with probiotics: An etiopathogenic approach at last?". Revista Española de Enfermedades Digestivas. 101 (8): 553-64.

[10] Bested, Alison C; Logan, Alan C; Selhub, Eva M (2013). "Intestinal microbiota, probiotics and mental health: from Metchnikoff to modern advances: part III - convergence toward clinical trials". Gut Pathogens. 5 (1): 4.

[11] Kim, Jae-Han; Block, David E.; Mills, David A. (2010). ""Simultaneous consumption of pentose and hexose sugars: an optimal microbial phenotype for efficient fermentation of lignocelluosic biomass.". Applied microbiology and biotechnology. 88.5: 1077-1085.

[12] R.J. Siezen, E.T. Van Hylckama Vlieg, (2011). Genomic diversity and versatility of Lactobacillus plantarum, a natural metabolic engineer Microb Cell Fact, 10 pp. 1-13

[13] M. Bernardeau, J.P. Vernoux, S. Henri-Dubernet, M. Guéguen, (2008). Safety assessment of dairy microorganisms: the Lactobacillus genus Int J Food Microbiol, 126, pp. 278-285

[14] D. Charalampopoulos, S.S. Pandiella, (2010). Survival of human derived Lactobacillus plantarum in fermented cereal extracts during refrigerated storage Lebensm-Wiss Technol, 43 pp. 431-435

[15] M. Krzywonos, T. Eberhard, (2011). High density process to cultivate Lactobacillus plantarum biomass using wheat stillage and sugar beet molasses Electron J Biotechnol, 14, p. 6

[16] K. Natarajan, A. Rajendran, (2012). Evaluation and optimization of food-grade tannin acyl hydrolase production by a probiotic Lactobacillus plantarum strain in submerged and solid state fermentation Food Bioprod Process, 90 pp. 780-792

[17] Silvestri, Guido; Hirao, Lauren A.; Grishina, Irina; Bourry, Olivier; Hu, William K.; Somrit, Monsicha; Sankaran-Walters, Sumathi; Gaulke, Chris A.; Fenton, Anne N.; Li, Jay A.; Crawford, Robert W.; Chuang, Frank; Tarara, Ross; Marco, Maria L.; Bäumler, Andreas J.; Cheng, Holland; Dandekar, Satya (2014). "Early Mucosal Sensing of SIV Infection by Paneth Cells Induces IL-1 $\beta$ Production and Initiates Gut Epithelial Disruption". PLoS Pathogens. 10 (8): e1004311.

[18] C.R. Soccol, P.S.L. Vandenberghe, M.R. Spier, (2010). The potential of probiotics: a review Food Technol Biotechnol, 48 pp. 413-434

[19] M. Céspedes, P. Cárdenas, M. Staffolani, M.C. Ciappini, G. Vinderola,(2013). Performance in nondairy drinks of probiotic $L$. casei strains usually employed in dairy products J Food Sci, 78, pp. 756-762

[20] S.J. Horn, S.I. Aspmo, V.G.H. Eijsink, (2005). Growth of Lactobacillus plantarum in media containing hydrolysates of fish viscera J Appl Microbiol, 99 pp. 1082-1089

[21] C.N. Heenan, M.C. Adams, R.W. Hosken, (2002). Growth medium for culturing probiotics bacteria for applications in vegetarian food products Lebensm-Wiss Technol, 35, pp. 171-176 
[22] Barthelmebs, L., Divies, C., and Cavin, J-F. (2001). Molecular characterization of the phenolic acid metabolism in the lactic acid bacteria Lactobacillus plantarum .

[23] Cleveland, J., Montville, T.J., Nes, I.F., Chikindas, M.L. (2001). Bacteriocins: safe, natural antimicrobials for food preservation. Int. J. Fd. Microbiol. 7:11-20.

[24] Daeschel, M.A. and Nes, I.F. (1995). Lactobacillus plantarum : physiology, genetics and applications in foods, in Food Biotechnology Microorganisms, Hui, Y.H. and Khachatourians, G.G., Eds., VCH Publishers, Inc., New York, chap. 21, pp. 721-743.

[25] Dedicatoria, R.F., Aspiras, R.B., and Sanchez, P.C. (1981). The fermentation inoculation with lactic acid bacteria to increase the nutritive value of sauerkraut, Kalikasan 10: 214-219.

[26] Dykstra, N.S., Hyde, L., Adawi, D., Kulik, D., Ahrné, S., Molin, G., Jeppsson, B., Mackenzie, A. \& Mack, D.R. (2011). Pulse probiotic administration induces repeated small intestinal Muc3 expression in rats. Pediatric Research 69: 206211.

[27] Fernández Gonzalez, M.J., García, P.G., Fernández, A.G., and Quintana, M.C.D. (1993). Microflora of the aerobic preservation of directly brined green olives from Hojiblanca cultivar, J. Appl. Bacteriol. 75: 226-233.

[28] Fleming, H.P. (1982). Fermented vegetables. In: Rose, A.H., ed. Economic Microbiology. Fermented Foods, Vol. 7. New York: Academic Press, pp. 227-258.

[29] Fuller, R. (1989). Probiotics in man and animals, J. Appl. Bacteriol. 66: 365368

[30] Hasslöf. P., Hedberg, M., Twetman, S. and Stecksén-Blicks, C. (2010). Growth inhibition of oral mutans streptococci and candida by commercial probiotic lactobacilli - an in vitro study. BMC Oral Health 10:18. doi: 10.1186/14726831-10-18

[31] Hütt, P., Shchepetova, J., Loivukene, K., Kullisaar, T. and Mikelsaar, M. (2006). Antagonistic activity of probiotic lactobacilli and bifidobacteria against entero- and urpathogens. Journal of Applied Microbiology 100: 1324-1332.

[32] Jacobsen, C.N., Rosenfeldt Nielsen, V., Hayford, A.E., Møller, P.L., Michaelsen, K.F., Pœrregaard, A., Sandström, B., Tvede, M., and Jakobsen, M. (1999). Screening of probiotic activities of forty-seven strains of Lactobacillus spp. by in vitro techniques and evaluation of the colonization ability of five selected strains in humans, Appl. Environ. Microbiol. 65: 4949-4956

[33] Johansson, M.L. (1995a). Systematics and starter culture selection of Lactobacillus for human intestine and Nigerian ogi, with special reference to Lactobacillus plantarum . Ph.D. thesis, Division of Food Technology, Lund University, Lund, Sweden.

[34] Johansson, M.-L., Molin, G., Jeppsson, B., Nobaek, S., Ahrné, S., and Bengmark, S. (1993). Administration of different Lactobacillus strains in fermented oatmeal soup: In vivo colonization of human intestinal mucosa and effect on the indigenous flora, Appl. Environ. Microbiol. 59: 15-20.

[35] Kandler, O. and Weiss, N. (1986). Regular, nonsporing Gram-positive rods, in Bergey's Manual of Systematic Bacteriology, Sneath, H.A., Mair, N.S., Sharpe, M.E. and Holt, J. Eds., Williams \& Wilkins, Baltimore, vol. 2, pp. 1208-1234.

[36] Kleerebezem, M., Boekhorst, J., van Kranenburg, R., Molenaar, D., Kuipers, O.P., Leer, R., Tarchini, R., Peters, S.A., Sandbrink, H.M., Fiers, M.W.E.J., Stiekema, W., Lankhorst, R.M.K., Bron, P.A., Hoffer, S.M., Groot, M.N.N., Kerkhoven, R., de Vries, M., Ursing, B., de Vos, W.M. and Siezen, R.J. (2003). Complete genome sequence of Lactobacillus plantarum WCFS1. Proc. Natl. Acad. Sci. U .S.A. 100: 1990-1995.

[37] Kono, Y. and Fridovich, I. (1983a). Isolation and characterization of the pseudocatalase of Lactobacillus plantarum : A new manganese containing enzyme, J. Biol. Chem . 258: 6015-6019.

[38] Kono, Y. and Fridovich, I. (1983b). Functional significance of manganese catalase in Lactobacillus plantarum, J. Bacteriol. 155: 742-746.

[39] Lönner, C. and Ahrné, S. (1995). Lactobacillus: Baking, in Food Biotechnology Microorganisms, Hui, Y.H. and Khachatourians, G.G., Eds., VCH Publishers Inc., Eureka, California, 797-844.

[40] Mack, D.R., Ahrné, S., Hyde, L., Wei, S. and Hollingsworth, M.A. (2003). Extracellular MUC3 mucin secretion follows adherence of Lactobacillus strains to intestinal epithelial cells in vitro. Gut 52: 827-833.

[41] Mack, D.R., Michail, S., Wei, S., McDougall L., and Hollingsworth, M.A. (1999). Probiotics inhibit enteropathogenic E.coli adherence in vitro by inducing intestinal mucin gene expression, Am. J. Physiol. 276: G941-G950.

[42] Mao, Y., Nobaek, S., Kasravi, B., Adawi, D., Stenram, U., Molin, G., and Jeppsson, B. (1996a). The effect of Lactobacillus strains and oat fiber on methotrexate-induced enterocolitis in rats, Gastroentereology 111: 334-344.

[43] McDonald, L.C., Shieh, D.H., Fleming, H.P., McFeeters, R.F., and Thompson, R.L. (1993). Evaluation of malolactic-deficient strains of Lactobacillus plantarum for use in cucumber fermentations, Food Microbiology 10: 489-99. 
[44] Michail, S. and Abernathy, F. (2002). Lactobacillus plantarum reduces the in vitro secretory response of intestinal epithelial cells to enteropathogenic Escherichia coli infection. Journal of Pediatric Gastroenterology and Nutrition 35: 350-355.

[45] Moorthy, S.N., and Mathew, G. (1998). Cassava fermentation and associated changes in physicochemical and functional properties, Crit. Rev. Fd. Sci. Nut. 38: 73-121.

[46] Nigatu, A. (1998). Systematics of Lactobacillus and Pediococcus isolated from fermented tef ( Eragrostis tef ) and kocho ( Ensete ventricosum ) and microbiological status of baked products, Ph.D. thesis, School of Graduate Studies, Addis Ababa University, Addis Ababa, Ethiopia.

[47] Osawa, R., Kuroiso, K., Goto, S. \& Shimzu, A. (2000). Isolation of tannindegrading lactobacilli from humans and fermented foods, Appl. Environ. Microbiol. 66: 3093-3097.

[48] Osman, N., Adawi, D., Ahrne, S., Jeppsson, B. \& Molin, G. (2005). Probiotic strains of Lactobacillus and Bifidobacterium affect the translocation and intestinal load of Enterobacteriaceae differently after Dgalactose-induced liver injury in rats. Microbial Ecology in Health and Disease 17: 40-46.

[49] Oyewole, O.B. and Odunfa, S.A. (1990). Characterization and distribution of lactic acid bacteria in cassava fermentation during fufu production, J. Appl. Bacteriol. 68: 145-152.

[50] Pulido, R.P., Omar, N.B., Abriouel, H., López, R.L., Canamero, M.M. and Gálvez (2005). Microbiological study of lactic acid fermentation of caper berries by molecular and culture dependant methods. Applied and Environmental Microbiology 71: 7872-7879.

[51] Söderling, E.M., Marttinen, A.M. and Haukioja, A.L. (2011). Probiotic lactobacilli interfere with Streptococcus mutans biofilm formation in vitro . Current Microbiology 62: 618-22.

[52] Tabasco, R., Sánchez-Patán, F., Monagas, M., Bartolomé, B., Moreno-Arribas, M.V., Peláez, C. \& Requena, T. (2011). Effect of grape polyphenols on lactic acid bacteria and bifidobacteria growth: Resistance and metabolism. Food Microbiology 28: 1345-1352.

[53] Vaquero, I., Marcobal, A. and Muñoz, R. (2004). Tannase activity by lactic acid bacteria isolated from grape must and wine. International Journal of Food Microbiology 96: 199-204.

[54] Wang, M., Adawi, D., Molin, G., Pettersson, B., Jeppsson, B. and Ahrné, S. (2001). Identification of the translocating bacteria in rats with acute liver injury and their relation to the bacterial flora of the intestinal mucosa, APMIS, 109: 551-558.

Citation: Asfaw Tora Kacho, "Industrial and Economic Importance of a Bacterium Lactobacillus Plantarum: A Review" International Journal of Research Studies In Biosciences (Ijrsb), Vol. 7, no. 7, pp. 13-19, 2019. http://Dx.Doi.org/10.20431/2349-0365.0707003

Copyright: (C) 2019 Authors. This is an open-access article distributed under the terms of the Creative Commons Attribution License, which permits unrestricted use, distribution, and reproduction in any medium, provided the original author and source are credited. 